Volume $10-2020 \mid$ n. 16

\title{
Mutações da Face Social do Estado pela Emenda Constitucional 95 e seus Efeitos sobre as Políticas Educacionais
}

\author{
Maria Vieira Silva \\ Ana Júlia Eugênio \\ Universidade Federal de Uberlândia (UFU), Uberlândia/MG - Brasil \\ Helen Corrêa Solis Neves \\ Centro Universitário do Triângulo (UNITRI), Uberlândia/MG - Brasil
}

\section{Resumo}

A Emenda Constitucional (EC) n. 95/2016, que Altera o Ato das Disposições Constitucionais Transitórias para instituir o Novo Regime Fiscal, provocará impactos substanciais no financiamento de políticas sociais brasileiras, no tempo presente. Problematizaremos a legitimidade da referida Emenda em relação aos dispositivos constitucionais de legalidade e razoabilidade presentes no ordenamento jurídico brasileiro, mediante uma pesquisa de natureza bibliográfica e documental. A análise dos documentos pautou-se no conteúdo das sete Ações Diretas de Inconstitucionalidade (ADI) ajuizadas no Supremo Tribunal Federal (STF), colocando em relevo os argumentos que sustentam a tese da inconstitucionalidade da Emenda, como contributos para fundamentar interpretações acerca do porvindouro comportamento face às ADI's protocoladas naquela instância. Serão abordados ainda os efeitos nocivos da EC nas metas do Plano Nacional de Educação, sobretudo aquelas que afetam diretamente o financiamento da educação.

Palavras-chaves: Emenda Constitucional n. 95/2016. Financiamento da Educação. Plano Nacional de Educação.

\section{Mutations of the State Social Face by Constitutional Amendment 95 and its Effects on Educational Policies}

\begin{abstract}
The Constitutional Amendment (CA) number 95/2016, which amends the Transitional Constitutional Provisions Act to establish the New Tax Regime, will have substantial impacts on the financing of Brazilian social policies, in the present time. We will question the legitimacy of the said Amendment in relation to the constitutional provisions of legality and reasonableness present in the Brazilian legal system, through a bibliographic and documentary research. The analysis of the documents was based on the content of the seven Direct Actions of Unconstitutionality (ADI) filed at the Supreme Federal Court, highlighting arguments that support the thesis of the Amendment's unconstitutionality, as contributions to support interpretations about the future behavior against the ADIs filed in that instance. The harmful effects of this Constitutional Amendment on the goals of the National Education Plan will also be addressed, especially those that directly affect the education funding.
\end{abstract}

Keywords: Constitutional Amendment number 95/2016. Education Funding. National Education Plan. 
Mutações da Face Social do Estado pela Emenda Constitucional 95 e seus Efeitos sobre as Políticas Educacionais

\section{Introdução}

Os direitos sociais - tais como Educação, Saúde, Previdência social, dentre outros -, estabelecidos pelo art. $6^{\circ}$ da Constituição Federal de 1988, conferem responsabilidade ao Estado no que se refere à proteção social dos cidadãos, vinculando as legislações infraconstitucionais ao mencionado dispositivo.

Em que pese a importância de tais determinações constitucionais concernentes à ação social do Estado, presenciamos potenciais retrocessos dessas conquistas, ensejados pela Emenda Constitucional (EC) n. ${ }^{\circ}$ 95/2016, a qual Altera o Ato das Disposições Constitucionais Transitórias, para instituir o Novo Regime Fiscal, e dá outras providências. Em razão da estrutura bicameral do Poder Legislativo, a mencionada Emenda tramitou na Câmara dos Deputados (PEC 241) e, posteriormente, no Senado Federal (PEC 85), obtendo a votação final, em segundo turno nessa última casa legislativa, no dia 16 de dezembro de 2016. Com efeito, instaurou-se um novo regime fiscal com um limite para os gastos do governo federal até 2036. Sua materialidade implica que os gastos da União ficarão limitados a um teto definido pelo montante do gasto do ano anterior reajustados pela inflação acumulada, medida pelo Índice Nacional de Preços ao Consumidor Amplo (IPCA). Tal medida se reverbera em um congelamento real das despesas totais do governo federal impactando na redução do gasto público em relação ao Produto Interno Bruto (PIB) e ao número de habitantes. Destarte, os gastos públicos não levarão em consideração o crescimento da renda e da população em seus cálculos, ocasionando austeridade fiscal e redução de investimentos em educação, saúde e seguridade social.

A aprovação da referida Emenda Constitucional ensejou muitas manifestações de diferentes setores da sociedade civil, sendo que várias instâncias alegaram seu caráter de inconstitucionalidade, gerando dissensos hermenêuticos no que tange à interpretação do referido dispositivo jurídico. Diante disso, o presente artigo pretende contribuir com o fomento desse debate problematizando a legitimidade da Emenda Constitucional 95, ancorando-se nas dimensões de legalidade e razoabilidade que pretendem sedimentar o ordenamento jurídico brasileiro, mediante as seguintes indagações: do ponto de vista jurídico-normativo, a EC 95 configura um ato inconstitucional? Em que medida a EC 95 compromete o financiamento das políticas sociais, e, em específico, da educação?

\section{Procedimentos Metodológicos}

Para o desenvolvimento das análises, realizamos um estudo de natureza bibliográfica e documental. O exame dos documentos pautou-se no conteúdo das sete Ações Diretas de Inconstitucionalidade ajuizadas no Supremo Tribunal Federal como também em manifestos produzidos por entidades acadêmicas sobre a referida Emenda.

Durante as manifestações contrárias em face à tramitação dos projetos que antecederam a Emenda 95 (PEC 241 na Câmara de Deputados e PEC 55 no Senado), além de contundentes argumentos de cariz político acerca da redução da atuação do Estado como provedor de direitos sociais, presenciamos também reiterados manifestos com narrativas sobre a inconstitucionalidade dos referidos projetos de Emenda Constitucional. Tais assertivas se mantiveram nos protestos ocorridos após a aprovação da supracitada Emenda. Com efeito, tendo como referência esse panorama de dissensos entre a maioria dos 
Mutaç̃es da Face Social do Estado pela Emenda Constitucional 95 e seus Efeitos sobre as Políticas Educacionais

representantes do parlamento brasileiro e vários segmentos da sociedade civil, iniciamos uma busca no portal do Supremo Tribunal Federal (STF) visando apreender se os argumentos que contestaram a Emenda Constitucional 95 haviam se materializado em proposições de Ação Direta de Inconstitucionalidade (ADI) no âmbito da suprema corte do Poder Judiciário. Assim, por meio do descritor "Emenda Constitucional 95/2016", realizamos buscas no âmbito do mencionado portal e localizamos sete ADI's protocoladas por entidades de diferentes origens, quais sejam:

- Associação dos Magistrados Brasileiros (AMB); Associação dos Juízes Federais do Brasil (AJUFE) e Associação Nacional dos Magistrados do Trabalho (ANAMATRA) ajuizaram a ADI 5633;

- Federação Nacional dos Servidores e Empregados Públicos Estaduais e do Distrito Federal (FENASEPE), ADI 5643;

- Partido Democrático Trabalhista (PDT), ADI 5558;

- Partido Socialismo e Liberdade (PSOL), ADI 5680;

- Partido dos Trabalhadores (PT), ADI 5715;

- Ministério Público - Conamp, ANPR e ANPT, ADI 5655;

- Confederação dos Trabalhadores da Educação (CNTE), ADI, 5734.

Destarte, foram selecionados apenas os processos ajuizados no STF que tinham por objeto a impugnação da Emenda Constitucional 95. O estudo pormenorizado dos documentos buscou apreender os argumentos que sustentam a tese da inconstitucionalidade da referida Emenda. Nesse processo foi evidenciado que, embora todas as ADI's tivessem como pressuposto comum a tese da inconstitucionalidade, o núcleo estruturante das alegações se diferenciava, ou seja, os arrazoados constantes dos documentos indicavam motivos distintos para sustentar interpretações acerca da inconstitucionalidade e os decorrentes apelos ao Supremo Tribunal Federal para a revogação do dispositivo em tela. Assim, colocaremos em relevo no decorrer do texto excertos das ADI's que indicam regularidades e singularidades no tratamento ensejado pelas instâncias proponentes.

Além do referido material empírico, constituem-se objeto de reflexão conceitos de Estado, Políticas Públicas e Constituição Dirigente. Tais conceitos possibilitam evidenciar as mutações e degenerescências dos direitos sociais no atual contexto, o qual é marcado pela ascensão e consolidação de políticas e práticas calcadas na doutrina neoliberal, que, por sua vez, se traduzem em dispositivos legais e se materializam nas agendas governamentais.

\section{Ambivalências no papel do Estado como ente regulador de políticas sociais: de provedor a desertor}

A categoria Estado é polissêmica e, como tal, agrega múltiplas definições, tornando-se, portanto, difícil abordar com profundidade as diferentes matrizes presentes na ciência política, dada a limitação espacial que essa seção comporta. Em diferentes contextos históricos, a problemática da configuração e função do Estado esteve presente contribuindo indubitavelmente para os diversos significados do termo e sua pluralidade de acepções. Embora haja diferenças paradigmáticas entre os contratualistas, sumariamente, podemos afirmar que um ponto comum entre os três autores clássicos dessa corrente (Hobbes 15881679; Locke 1632-1704 e Rousseau, 1712-1778) diz respeito à premissa de que a origem do 
Estado se substantiva no contrato social. Sob tal perspectiva, ancorados na ideia de um consenso para garantir o bem comum na existência social, os contratualistas asseveram que o Estado se constitui em uma entidade social para enfrentar e vencer os conflitos, barbáries e desvantagens do "Estado de natureza", obviamente, sob a égide da doutrina liberal. De acordo com Hofling (2001, p. 36),

As teorias políticas liberais concebem as funções do Estado essencialmente voltadas para a garantia dos direitos individuais, sem interferência nas esferas da vida pública e, especificamente, na esfera econômica da sociedade. Entre os direitos individuais, destacam-se a 'propriedade privada como direito natural' (Locke, 1632-1704), assim como o direito à vida, à liberdade e aos bens necessários para conservar ambas. $\mathrm{Na}$ medida em que o Estado, no capitalismo, não institui, não concede a propriedade privada, não tem poder para interferir nela.

A partir de concepções políticas e epistemológicas distintas e em outro contexto social, Karl Marx (1818-1883) e Friedrich Engels (1588-1679) elaboram teorizações sobre o Estado, contrapondo-se aos pressupostos hegeliano. Ao romper com a ideia de Estado moderno em Hegel, os autores criticam a dimensão reificada e a dualidade existente entre sociedade civil e Estado. Destarte, Hegel

[...] pressupôs a separação civil e do Estado político (uma situação moderna) e a desenvolveu como momento necessário da ideia, como verdade absoluta racional. Apresentou o Estado político na sua forma moderna da separação dos diferentes poderes. Ao estado real e agente, ele deu a burocracia como seu corpo e colocou esta, como o espírito que sabe, acima do materialismo da sociedade civil. Opôs o universal em si existente do Estado aos interesses particulares e à necessidade civil. Em uma palavra, ele expõe, por toda a parte, o conflito entre sociedade civil e Estado (MARX, 2010, p. 91).

Com efeito, sob a perspectiva hegeliana, o Estado assume uma forma etérea que transcende e paira sobre a sociedade civil. Por outro prisma, Marx e Engels formulam uma concepção de Estado a partir de nexos entre a sociedade civil e a sociedade política tangenciada pela correlação de forças entre as classes e estratos sociais por meio dos conflitos e contradições presentes nos aparelhos do Estado, que o definem e o constituem. Isso nos remete a pensar o Estado de forma "dessacralizada", contrapondo-se às perspectivas reificadas deste ente; ao contrário, sua existência se plasma nas contradições das classes sociais existentes na sociedade. Para Marx,

[...] as relações humanas ligadas a este modo de produção e por ele engendradas constitui a sociedade civil nos seus diferentes estádios, como sendo o fundamento de toda a história. Isto equivale a representá-la na sua ação enquanto Estado, a explicar através dela o conjunto das diversas produções teóricas e das formas da consciência, religião, moral, filosofia etc., e a acompanhar o seu desenvolvimento a partir destas produções; o que permite naturalmente representar a coisa na sua totalidade (MARX, 2010, p. 52).

As contribuições de Marx para a desconstrução de uma perspectiva fetichizada do Estado, como algo transcendental, imanente e superior, foram essenciais para imprimir seu caráter concreto e histórico, fundamentado em uma concepção de história que tem como base o desenvolvimento do processo real da produção, contritamente a produção material da vida imediata. 
Mutaç̃es da Face Social do Estado pela Emenda Constitucional 95 e seus Efeitos sobre as Políticas Educacionais

Também nas formulações gramscianas, produzidas em um contexto mais recente - e ampliando alguns aspectos das teses marxianas de Estado - a sociedade política e a sociedade civil estão imbricadas, se mesclam e se encontram indissociadas, assim, a distinção que o autor faz entre ambas as esferas é apenas de cariz metodológico. Sob a ótica de Gramsci, a sociedade civil é constituída por um conjunto heterogêneo de entidades nomeadas como aparelhos privados de hegemonia que disputam consensos e operam pela dominação política e ideológica, por meio da elaboração e/ou difusão de visões de mundo. A sociedade política, por sua vez, se apresenta como o aparelho de coerção estatal, mediante força sobre focos de resistência, sobretudo nos momentos de crise no comando e na direção, nos quais desaparece o consenso espontâneo (GRAMSCI, 2000). Sob tal perspectiva, o Estado atua por meio de força, consenso e coerção legal, criando estratégias para uma dominação sutil e tácita. Essa teorização ficou conhecida como a "concepção ampliada" do Estado, com a inclusão, dentro do próprio Estado, dos aparelhos hegemônicos para sustentação da lógica capitalista.

Sem embargo, as conceituações e composições do Estado vão se metamorfoseando, mas permanece a recorrente função deste ente de dar sustentação ao funcionamento da sociedade capitalista. No contexto atual, presenciamos a crise dos Estados-providência e a reconfiguração dos espaços público e privado. Tais mudanças são substancialmente influenciadas pela ascensão da doutrina neoliberal, o arrefecimento do papel do Estado como provedor de políticas sociais e agendas governamentais com prevalência da lógica mercantil. Torna-se importante aqui ressaltar a diferenciação entre Estado e governo. Para Hofling (2001, p. 31),

[...] é possível se considerar Estado como o conjunto de instituições permanentes como órgãos legislativos, tribunais, exército e outras que não formam um bloco monolítico necessariamente - que possibilitam a ação do governo; e Governo, como o conjunto de programas e projetos que parte da sociedade (políticos, técnicos, organismos da sociedade civil e outros) propõe para a sociedade como um todo, configurando-se a orientação política de um determinado governo que assume e desempenha as funções de Estado por um determinado período.

Sob tal prisma, políticas públicas são entendidas como o "Estado em ação", ou seja, é o Estado implantando um projeto de governo através de programas, de ações voltadas para setores específicos da sociedade (HOFLING, 2001, p. 31).

Com efeito, no atual contexto, Estado e governo tornam-se cada mais inabilitados, seja para regular a própria economia nacional, quanto para regular as políticas públicas, em razão do poderio do mercado. De acordo com Santos,

\begin{abstract}
O Estado fraco, que emerge do Consenso de Washington, só é fraco ao nível das estratégias de hegemonia e de confiança. Ao nível da estratégia de acumulação é mais forte do que nunca, na medida em que passa a competir ao Estado gerir e legitimar no espaço nacional as exigências do capitalismo mundial. Não se trata, pois, da crise do Estado em geral, mas de um certo tipo de Estado. Não se trata do regresso puro e simples do princípio do mercado, mas de uma nova articulação, mais directa e mais íntima, entre o princípio do Estado e o princípio do mercado (apud AFONSO, 2000, p. 1143).
\end{abstract}

Corroboramos as assertivas acima, uma vez que a máquina estatal segue com uma estrutura dotada de vigor, não obstante a crise, se consubstancia em um modelo estatal que se sustenta como garantidor de direitos sociais e democráticos. Afonso (2000), ao realizar 
Mutações da Face Social do Estado pela Emenda Constitucional 95 e seus Efeitos sobre as Políticas Educacionais

reflexões sobre o Estado e os processos de regulação, destaca a correlação entre as crises cíclicas do capital e a crise do Estado, desenvolvendo a tese de que há protagonismos instáveis entre essas duas esferas. Para o autor, as interações protagonizadas alternadamente entre o Estado e o mercado ocorrem com o predomínio frequente do primeiro, e a subsequente subalternização e duradoura colonização da comunidade.

$\mathrm{Na}$ realidade brasileira, é possível afirmar que presenciamos certo protagonismo do Estado (em sua dimensão ampliada, compondo-se da sociedade civil e sociedade política) por ocasião da elaboração da Constituição Federal de 1988. Após 21 anos de Regime Militar no Brasil, em 1987, foi instalada a Assembleia Nacional Constituinte a partir das eleições de novembro de 1986. Anterior a esse acontecimento, no final da década de 1970 e início da década de 1980, a sociedade brasileira já vivia o "sopro" da redemocratização em decorrência da amenização da supremacia do Poder Executivo - representado pelos militares - e a rearticulação dos movimentos sociais da sociedade civil que se contrapunham à ordem social vigente. A mobilização dos vários segmentos da população em prol de uma maior participação política inicialmente culminou no direito às Emendas Populares. Previstas no regimento da Assembleia Constituinte, cada Emenda deveria ter, no mínimo, 30 mil assinaturas de eleitores. Com efeito, das 122 emendas populares apresentadas, 83 foram aceitas por atenderem aos requisitos regimentais. Elas versavam sobre os temas mais diversos, como reforma agrária, direitos trabalhistas, direitos da criança e do adolescente, direitos indígenas, criação de novos Estados, saúde, educação, participação popular, eleições diretas para presidência em 1988, comunicação social e família (2013).

Com efeito,

A Carta Magna afirmou preceitos caros à democracia e aos direitos sociais, produzidos em meio à arena de disputa na (re)definição de forças e de grupos políticos. Marcada por interpretações díspares, a CF aprovada pela Assembleia Nacional Constituinte, não raro, é avaliada como 'extremante detalhada' ou, por outros, como uma das mais completas constituições do mundo.

A Constituição Federal de 1988 é também caracterizada pela doutrina jurídica como Constituição dirigente, cuja conceituação foi formulada por José Joaquim Gomes Canotilho. As cartas constitucionais categorizadas nessa tendência estão vinculadas à perspectiva do novo constitucionalismo e têm em comum o fato de serem elaboradas em contextos pósditatoriais e com prevalência da dimensão subjetiva dos direitos sociais. Sob tal prisma, a democracia está organicamente vinculada ao poder popular e deve ser fundamentada na própria constituição, como também as deliberações políticas devem estar abalizadas no que prevê o texto constitucional. O Estado deve decidir o desempenho de suas atividades, bem como de todos os órgãos de sua titularidade, de forma vinculada às normas constitucionais.

[...] a teoria da constituição assume-se como teoria da constituição dirigente enquanto problematiza a tendência das leis fundamentais para: (1) se transformarem em estatutos jurídicos do estado e da sociedade; (2) se assumirem como norma (garantia) e tarefa (direcção) do processo político-social (CANOTILHO, 1994, p. 169).

Em consonância com a perspectiva da tendência constitucional dirigente, a Constituição Federal da República Federativa do Brasil de 1988, dentre seus princípios, dispõe sobre o Estado democrático de direito; a cidadania; a dignidade da pessoa humana; pluralismo político. E em seu Artigo $3^{\circ}$ defende como objetivos fundamentais, dentre outros, a construção 
de sociedade livre, justa e solidária; a erradicação da pobreza e da marginalização, bem como a redução das desigualdades sociais ${ }^{1}$ e regionais; a promoção do bem de todos, sem preconceitos de origem, raça, sexo, cor, idade e quaisquer outras formas de discriminação.

Com efeito, mesmo nos limites de uma sociedade de base liberal, a Constituição Federal de 1988, alcunhada por Ulisses Guimarães ${ }^{2}$ de "Constituição-Cidadã", incorporou princípios ligados aos direitos sociais, ao Estado Democrático de Direito com dispositivos normativos que visam a mitigar a desigualdade social e as diferentes formas de discriminação. Na esfera dos Direitos Sociais, e, em específico, no campo da educação tivemos avanços significativos, uma vez que a referida Carta Magna prevê mecanismos de proteção jurídica de direitos subjetivos, mediante a possibilidade de exigir-se, de maneira garantida, por parte do Estado, essa prerrogativa, como algo próprio ao sujeito e garantidor da dignidade humana. Assim, a responsabilidade do Estado para com as garantias fundamentais se reverbera também na obrigatoriedade do financiamento dos direitos sociais, mediante dispositivos de obrigatoriedade para aplicação mínima de recursos, em vinculações de receita e responsabilização dos entes federados:

Art. 212. A União aplicará, anualmente, nunca menos de dezoito, e os Estados, o Distrito Federal e os Municípios vinte e cinco por cento, no mínimo, da receita resultante de impostos, compreendida a proveniente de transferências, na manutenção e desenvolvimento do ensino.

[....]

$\S 3^{\circ} \mathrm{A}$ distribuição dos recursos públicos assegurará prioridade ao atendimento das necessidades do ensino obrigatório, no que se refere a universalização, garantia de padrão de qualidade e equidade, nos termos do plano nacional de educação. (Redação dada pela Emenda Constitucional $n^{\circ} 59$, de 2009)

$\S 4^{\circ}$ - Os programas suplementares de alimentação e assistência à saúde previstos no art. 208, VII, serão financiados com recursos provenientes de contribuições sociais e outros recursos orçamentários.

$\S 5^{\circ} \mathrm{A}$ educação básica pública terá como fonte adicional de financiamento a contribuição social do salário-educação, recolhida pelas empresas na forma da lei. (Redação dada pela Emenda Constitucional $n^{\circ} 53$, de 2006)

$\S 6^{\circ}$ As cotas estaduais e municipais da arrecadação da contribuição social do salárioeducação serão distribuídas proporcionalmente ao número de alunos matriculados na educação básica nas respectivas redes públicas de ensino. (Incluído pela Emenda Constitucional $n^{\circ}$ 53, de 2006) (BRASIL, 1988, art. 2012).

Não obstante, nos contextos posteriores à sua promulgação, a Constituição Federal de 1988 tem sido recorrentemente alterada por meio de Emendas Constitucionais, as quais, via de regra, têm alterado sua face social, podendo comprometer de forma expressiva conquistas cidadãs no campo dos direitos sociais, como é o caso da Emenda Constitucional 95, a qual provocará, de forma inequívoca, vicissitudes para os direitos sociais.

A Emenda Constitucional 95 foi uma demanda induzida da esfera executiva para a legislativa e, após sua aprovação, foram protocolados sete Ações Diretas de

1 Tal princípio constitucional se consubstanciou em políticas de Estado, como o bolsa -família, a Lei $\mathrm{n}^{\circ}$ 12.711/2012 (Lei de Cotas), Lei n 11.340/2006 (Lei Maria da Penha), entre outras.

2 Ulysses Silveira Guimarães (1916-1992), filiado ao Partido Movimento Democrático Brasileiro (PMDB), tomou posse como presidente da Assembleia Nacional Constituinte, em $1^{\circ}$ de fevereiro de 1987, responsável por estabelecer nova Constituição para o Brasil, após 21 anos de vigência do regime militar. 
Mutações da Face Social do Estado pela Emenda Constitucional 95 e seus Efeitos sobre as Políticas Educacionais

Inconstitucionalidade no Supremo Tribunal Federal, requerendo a sua revogação. As interseções entre essas instâncias no que tange à materialidade dos dispositivos legais estão alicerçadas na estrutura do Estado Moderno mediante a dinâmica da tripartição dos poderes. De acordo com o artigo $2^{\circ}$ da Constituição Federal brasileira "[...] são Poderes da União, independentes e harmônicos entre si, o Legislativo, o Executivo e o Judiciário". O referido dispositivo constitucional para a organização do Estado brasileiro está em consonância com a teoria da tripartição do Poder do Estado, preconizada por Aristóteles e Montesquieu.

Visando circunstanciar a tramitação da PEC 241 e da PEC 85, vale ressaltar que o art. 60 da Constituição Federal dispõe sobre o procedimento de proposição de emendas à Constituição. De acordo com o referido artigo, a proposta deverá ser apresentada por um terço, no mínimo, dos membros da Câmara dos Deputados ou do Senado Federal, ou pelo Presidente da República, ou por mais da metade das Assembleias Legislativas das unidades da Federação.

Ao ser apresentada, a proposta será analisada pela Comissão de Constituição e Justiça, que realizará uma análise técnica acerca da admissibilidade, levando em conta a constitucionalidade, legalidade e técnica administrativa, sem entrar, propriamente, no mérito da proposta de emenda. Se aprovada na Comissão de Constituição e Justiça, será criada uma comissão especial para apurar a análise de conteúdo. Na fase seguinte, a proposta será votada em cada casa do Congresso Nacional (Câmara dos Deputados e Senado Federal). No âmbito da estrutura bicameral de nosso Congresso Nacional, a Câmara dos Deputados representa a vontade popular e, o Senado Federal, os estados da Federação. Assim, para ser aprovada uma emenda à Carta Magna, é condição sine qua non três quintos dos votos dos respectivos membros, que, na Câmara dos Deputados, corresponde atualmente a 308 votos e, no Senado Federal, 41 votos. Após a aprovação, a emenda será promulgada pelas Mesas da Câmara dos Deputados e do Senado Federal. Constatada a publicação da Emenda à Constituição, realizada pelas Mesas da Câmara dos Deputados e do Senado Federal, há a produção de efeitos de imediato, eis que as emendas à Constituição não se submetem ao período de vacatio legis cujo termo se traduz na vacância da lei, ou seja, o período concernente ao dia que a lei entra em vigor e sua produção de efeitos.

Para que uma lei possa vigorar no ordenamento jurídico brasileiro, é imprescindível sua consonância com a Constituição Federal, hierarquicamente superior aos demais diplomas normativos e que se dispõe de todos os parâmetros necessários ao funcionamento do Estado brasileiro (Fonte: <https://www2.camara.leg.br>. Acesso em: 02 dez. 2018).

Desse modo, o Poder Judiciário, por meio do Supremo Tribunal Federal (STF), realiza, como uma de suas funções, a averiguação de compatibilidade entre as leis editadas pelo poder legislativo e a Constituição, com o chamado controle repressivo de Constitucionalidade, salvaguardado o controle preventivo que é realizado pela Comissão de Constituição e Justiça, anteriormente à promulgação da lei. $O$ controle concentrado repressivo de constitucionalidade, a ser realizado pelo STF, se dá por meio de provocação, tendo como meio adequado a Ação Declaratória de Constitucionalidade (ADC), Ação direta de inconstitucionalidade (ADI), Ação Direta de Inconstitucionalidade por Omissão (ADO) e Arguição de Descumprimento de Preceito Fundamental (ADPF).

Vale ressaltar que a Ação Declaratória de Constitucionalidade visa confirmar a constitucionalidade de determinada lei, quando houver sido suscitada alguma dúvida a 
Mutações da Face Social do Estado pela Emenda Constitucional 95 e seus Efeitos sobre as Políticas Educacionais

respeito da sua compatibilidade com a Constituição. Já a Ação Direta de Inconstitucionalidade por Omissão é relativa à omissão do poder legislativo na criação de leis que visam a efetivação de direitos constitucionalmente previstos. A Arguição de Descumprimento de Preceito Fundamental se refere à reparação de qualquer lesão a preceito fundamental decorrente de ato do Poder Público. Na seção a seguir, faremos uma análise do conteúdo das Ações Diretas de Inconstitucionalidade da Emenda 95 protocoladas no Supremo Tribunal Federal.

\title{
Argumentos das Ações Diretas de Inconstitucionalidade face à Emenda 95
}

No dia 15 de junho de 2016, o então Ministro da Economia, Henrique de Campos Meirelles, encaminhou a Michel Temer, naquela ocasião Vice-Presidente da República no exercício do cargo de Presidente da República, o documento EMI n 00083/2016 MF MPDG, no qual apresentava a Proposta de Emenda à Constituição para criar o Novo Regime fiscal no âmbito da União. De acordo com os argumentos de Meirelles (2016, s. p.),

\begin{abstract}
Nos últimos anos, aumentaram-se gastos presentes e futuros, em diversas políticas públicas, sem levar em conta as restrições naturais impostas pela capacidade de crescimento da economia, ou seja, pelo crescimento da receita. É fundamental para o equilíbrio macroeconômico que a despesa pública seja gerida numa perspectiva global. Nesse sentido, qualquer iniciativa que implique aumento de gastos não deve ser analisada isoladamente, haja vista que essa abordagem tende a levar a conclusões equivocadas sobre seus benefícios e custos. De fato, nossa experiência ensinou que o processo descentralizado e disperso de criação de novas despesas gerou crescimento acelerado e descontrolado do gasto. Isso posto, faz-se necessário a introdução de limites ao crescimento da despesa global, ao mesmo tempo em que se preservam as prerrogativas dos poderes constituídos para alocarem os recursos públicos de acordo com as prioridades da população e a legislação vigente.
\end{abstract}

Com efeito, de acordo com o discurso de seu proponente, a referida Proposta institui o programa denominado Novo Regime Fiscal (NRF), com vigência pré-fixada de 20 anos ou 20 exercícios financeiros.

\footnotetext{
O Novo Regime Fiscal, válido para União, terá duração de vinte anos. Esse é o tempo que consideramos necessário para transformar as instituições fiscais por meio de reformas que garantam que a dívida pública permaneça em patamar seguro. Tal regime consiste em fixar meta de expansão da despesa primária total, que terá crescimento real zero a partir do exercício subsequente ao de aprovação deste PEC, o que levará a uma queda substancial da despesa primária do governo central como porcentagem do PIB. Trata-se de mudar a trajetória do gasto público federal que, no período 1997-2015 apresentou crescimento médio de $5,8 \%$ ao ano acima da inflação. 10 . Por ser de duração previamente estabelecida, o Novo Regime Fiscal será inscrito no Ato das Disposições Constitucionais Transitórias. Fixa-se, para o exercício de 2017, limite equivalente à despesa realizada em 2016, corrigida pela inflação observada em 2016. A partir do segundo exercício, o limite para a despesa primária será naturalmente incorporado ao processo de elaboração da lei de diretrizes orçamentárias e da lei orçamentária anual, e consistirá no valor do limite do exercício anterior, corrigido pela inflação do exercício anterior. Tal correção será feita pelo Índice Nacional de Preços ao Consumidor Amplo (IPCA) (MEIRELLES, 2016, s. p.).
}

Além da exposição de motivos presente no documento supracitado, Meirelles (2016) apresenta também o teor da Proposta de Emenda Constitucional, o qual visa alterar o Ato das 
Mutações da Face Social do Estado pela Emenda Constitucional 95 e seus Efeitos sobre as Políticas Educacionais

Disposições Constitucionais Transitórias da Constituição Federal, para instituir o Novo Regime Fiscal.

Considerando que o Brasil adota o sistema bicameral do tipo federativo, conforme dispõe o artigo 44 da Constituição Federal ${ }^{3}$, o Congresso Nacional se compõe da Câmara dos Deputados e do Senado Federal. Assim, seguindo os ritos de tramitação de grande parte dos dispositivos legais, a mencionada proposta foi protocolada na Casa Iniciadora - a Câmara dos Deputados, e, após sua aprovação, foi encaminhada para a Casa Revisora -, o Senado Federal.

Chegada a PEC 241/2016 à Câmara dos Deputados, a Mesa Diretora encaminhou a proposição, que tramitou em regime especial, à Comissão de Constituição e Justiça e de Cidadania (CCJC) para análise da admissibilidade da proposta. Na CCJC foi designado o Deputado Danilo Forte como relator da matéria. Em 29 de julho de 2016 foi apresentado e votado o parecer. O referido relator opinou que a Proposta de Emenda à Constituição respeitava os requisitos formais previstos na Constituição Federal e no Regimento Interno da Câmara dos Deputados, a saber: iniciativa do Poder Executivo; ausência de estado de sítio, de defesa ou intervenção federal; e o fato de a matéria tratada na proposta não ter sido objeto de outra PEC rejeitada ou tida por prejudicada pela sessão legislativa.

No âmbito da Câmara dos Deputados, o relator da Proposta foi Darcísio Perondi (PMDB). De acordo com o relatório da Comissão Especial da Câmara dos Deputados, de autoria do referido deputado,

[...] não se verificou qualquer dispositivo que atente contra a forma federativa de Estado, o voto direto, secreto, universal e periódico, a separação dos Poderes, ou contra os direitos e garantias individuais. Isso porque o Novo Regime Fiscal assegura que os limites mínimos a serem aplicados nas despesas com ações e serviços públicos de saúde e CÂMARA DOS DEPUTADOS Comissão Especial - Proposta de Emenda à Constituição n 241-A, de 2016 Página 8 de 56 com manutenção e desenvolvimento de ensino crescerão exatamente pelo índice inflacionário. Dessa forma, mantém-se a obrigatoriedade de aplicação mínima nos setores tratados, garantindo a materialização do direito de acesso universal à saúde e à educação, evitando que esses valores sejam impactados por quedas de arrecadação, como as que têm sido percebidas nos últimos anos (PERONDI, 2016, p. 25).

O relator argumenta ainda:

Temos que compreender que o Novo Regime Fiscal se traduzirá num maior empoderamento do Legislativo, que fortalecerá, ao mesmo tempo, sua autonomia e sua responsabilidade para alocar recursos do Orçamento, ante as prioridades dinâmicas de um país em permanente transformação como este, sem as amarras das múltiplas vinculações. Sob o novo regime, o Brasil chega à era da maturidade orçamentária, sem maquiagens de números, sem ficções financeiras, com maior correspondência entre os valores autorizados e aqueles executados. De fato, com a imposição de limites para as despesas, o orçamento votado pelo Legislativo refletirá escolhas realistas de alocação de recursos nas diversas políticas públicas (PERONDI, 2016, p. 27).

No âmbito do Senado, a Proposta recebeu a designação de PEC 85 e o seu relator na referida casa foi o senador Eunício de Oliveira, o qual também argumentou favoravelmente

3 Art. 44. O Poder Legislativo é exercido pelo Congresso Nacional, que se compõe da Câmara dos Deputados e do Senado Federal. 
Mutações da Face Social do Estado pela Emenda Constitucional 95 e seus Efeitos sobre as Políticas Educacionais

em prol do Projeto de Emenda Constitucional. No que concerne ao conteúdo material da PEC, apresenta as seguintes assertivas, de natureza econômica:

[...] desde a Constituição de 1988, os gastos públicos cresceram continuamente. Conforme aponta a justificação da PEC, entre 1997 e 2015, as despesas primárias cresceram $5,7 \%$ por ano em termos reais, muito acima do crescimento do PIB, que não atingiu $3 \%$ ao ano, ou seja, nosso desequilíbrio fiscal tem origem no aumento continuado da despesa primária. $O$ fato de, durante boa parte deste milênio, as receitas terem crescido também em ritmo mais acelerado do que o PIB, o que não tende a se repetir no futuro, apenas mascarou nossa situação fiscal, dando a impressão de que havia um equilíbrio duradouro das contas públicas. Bastou, entretanto, que as receitas primárias passassem a ter um comportamento mais normal, crescendo em ritmo compatível com o crescimento do PIB, para a dívida pública passar a crescer de forma preocupante. A relação dívida bruta/PIB passou de 52\%, ao final de 2013, para 67\%, ao final de 2015 . É necessário reequilibrar as contas públicas para conter o crescimento da relação dívida/PIB. Em vez de proceder aos ajustes traumáticos, em vez de fazer isso... É melhor do que fazer ajustes traumáticos como os que foram necessários na Grécia. O Novo Regime Fiscal permitirá a manutenção dos gastos públicos em termos reais. Contudo, à medida que o PIB crescer, a parcela correspondente à participação do Governo deverá diminuir. Isso beneficiará o crescimento por meio de dois canais principais: aumento da poupança pública e redução do endividamento. Cria-se, assim, um ambiente propício para a redução da taxa de juros e a ancoragem das expectativas dos agentes econômicos. Isso induzirá ao aumento do investimento e terá repercussões positivas sobre a taxa de crescimento da economia (OLIVEIRA, 2016, p. 2).

A referida PEC obteve a seguinte votação no âmbito do Senado: 52 senadores votaram a favor e 16 senadores votaram contra. O clima político favorável ao Executivo Federal em 2016 possibilitou a indução de medidas provisórias, Projetos de Emendas Constitucionais e Decretos, o que foi apoiado e fortemente defendido pela maioria da instância legislativa. Sem embargo, o Poder Judiciário, ao qual compete a função de "guardião da Constituição", pode se contrapor às instâncias Executiva e Legislativa, visando a afirmação de direitos fundamentais, mediante limites substantivos às deliberações políticas emanadas das referidas instâncias. Referenciando-se nessa prerrogativa e nos incisos VIII e IX do artigo $103^{4}$ da Constituição Federal, alguns partidos políticos, entidades de classe e confederações sindicais, protocolaram Ações Diretas de Inconstitucionalidade no Supremo Tribunal Federal. As referidas Ações apresentam alguns argumentos de natureza distinta, mas todas sustentam a tese comum da inconstitucionalidade da Emenda.

A primeira ADI (n 5633) foi ajuizada em 16/12/2016 pelas três principais associações nacionais dos magistrados, quais sejam: a Associação dos Magistrados Brasileiros (AMB); a Associação dos Juízes Federais do Brasil (AJUFE) e a Associação Nacional dos Magistrados do Trabalho (ANAMATRA). A referida Ação apresenta em seu teor argumentos de cariz corporativo ao asseverar que o novo regime fiscal adotado pela Emenda "[...] está limitando e restringindo a autonomia administrativa e financeira do Poder Judiciário de participar da elaboração do seu próprio orçamento".

\footnotetext{
4 Art. 103. Podem propor a ação direta de inconstitucionalidade e a ação declaratória de constitucionalidade: [...] VIII - partido político com representação no Congresso Nacional; IX - confederação sindical ou entidade de classe de âmbito nacional.
} 
Mutações da Face Social do Estado pela Emenda Constitucional 95 e seus Efeitos sobre as Políticas Educacionais

No que concerne à Ação Direta de Inconstitucionalidade de $n^{\circ} 5643$, ajuizada pela Federação Nacional dos Servidores e Empregados Públicos Estaduais e do Distrito Federal (FENASEPE), tem-se como argumentação, que visa combater as disposições da Emenda Constitucional 95, o impedimento do desenvolvimento econômico e social, elencando que as bases que ensejaram a criação da emenda constitucional são equivocadas, em razão da ausência de comprovação do descontrole das contas públicas e crescimento de despesas primárias que originam crise econômica e fiscal. Aduzem, ainda, afronta aos princípios da proteção da confiança, da vedação ao retrocesso e dignidade humana, uma vez que serviços públicos como educação, assistência jurídica, assistência social serão sucateados com a vigência das cláusulas do novo regime fiscal.

No que se refere aos argumentos contidos na Ação Direta de Inconstitucionalidade $\mathrm{n}^{\circ}$ 5658, ajuizada pelo Partido Democrático Trabalhista (PDT), é elencada a violação ao princípio da proporcionalidade, esvaziando um dos principais aspectos da democracia que se materializa na decisão sobre a adequada alocação dos recursos públicos, acarretando afronta ao princípio democrático bem como à clausula pétrea contida no art. 60 , $\S 4^{\circ}$, II da Constituição Federal. Aduz que o congelamento dos pisos constitucionais de gastos com saúde e educação violam clausula pétrea, que impede a deliberação por meio de Emenda Constitucional de assuntos que concernem a direitos e garantias fundamentais.

Adentrando na Ação Direta de Inconstitucionalidade n. 5680, ajuizada pelo Partido Socialismo e Liberdade (PSOL), o requerente também aponta inconstitucionalidade em razão de ofensa a cláusulas pétreas, bem como afronta aos princípios da vedação ao retrocesso social como limite implícito ao poder de reforma da Constituição, que deve ser compreendido como um compromisso com políticas e atuações que busquem alterar o status social para minorar desigualdades, proteger os vulneráveis e efetivar o princípio da igualdade material. Aduzem, ainda, violação ao princípio do mínimo existencial, bem como ofensa ao art. $5^{\circ}, \S 3^{\circ}$ da Constituição, em que a norma impugnada seria contrária a tratados interacionais de direitos humanos incorporados ao ordenamento jurídico brasileiro, tais como a Carta da Organização das Nações Unidas, o Pacto Internacional sobre Direitos Econômicos, Sociais e Culturais (PIDESC), a Convenção Americana sobre Direitos Humanos e o Protocolo de São Salvador.

Argumenta, ainda, que o congelamento dos gastos públicos por 20 anos, sem a possibilidade de alteração significativas na destinação dos recursos, é incompatível com o pluralismo político, que se insere como clausula pétrea implícita bem como o voto direto, secreto, universal e periódico (também inserido no rol das cláusulas pétreas - art. $60 \S 4^{\circ}$ ). Menciona, ainda, afronta à soberania popular, uma vez que Congresso Nacional e Presidente da República estarão limitados ao exercício das atribuições relacionadas ao processo legislativo em matéria orçamentária, com a consequente violação à igualdade de chances dos partidos políticos.

A Ação Direta de Inconstitucionalidade $n^{\circ} 5715$, ajuizada pelo Partido dos Trabalhadores (PT), apresenta argumentos de cariz formal, como a violação ao art. 363 do Regimento Interno do Senado Federal, que aduz que a proposta de Emenda Constitucional deve ser debatida em três sessões ordinárias. No que concerne à alegação de inconstitucionalidade material, aduz que a norma atingiu diretamente a identidade da Constituição, fundada na promoção dos direitos sociais e na diminuição das desigualdades. Alega, também, violação a cláusulas pétreas, uma vez que o estabelecimento de teto dos gastos públicos dificultará a relação das 
Mutações da Face Social do Estado pela Emenda Constitucional 95 e seus Efeitos sobre as Políticas Educacionais

prestações estatais para prover as demandas decorrentes do direito à saúde e à educação. Assevera ainda que os direitos sociais devem ser compreendidos como diretos fundamentais, de maneira que se afiguram também como cláusulas pétreas.

A Ação Direta de Inconstitucionalidade interposta pela Confederação dos Trabalhadores da Educação (CNTE), ao apresentar a educação como central em seu conteúdo, afirma que o

\begin{abstract}
[...] congelamento por vinte anos dos repasses tributários dos entes federativos para a educação impactará no oferecimento do ensino básico por parte do Estado, de modo a ampliar as desigualdades sociais, econômicas e regionais, em notória afronta ao princípio da isonomia em sua acepção material (art. $5^{\circ}$, caput) e de modo a inviabilizar o pleno exercício dos direitos à liberdade individual e à autonomia privada (art. $5^{\circ}$, caput e incisos IV, VI, IX e XIII), em prejuízo direto à própria dignidade humana (art. $\left.1^{\circ}, \mathrm{III}\right)$, que configuram cláusulas pétreas (garantias individuais), a teor do artigo $60, \S 4^{\circ}, \mathrm{IV} .2$ ) (ADI..., 2017).
\end{abstract}

Por fim, no que se refere à Ação Direta de Inconstitucionalidade 5655, ajuizada pela Associação Nacional dos Membros do Ministério Público (CONAMP), Associação Nacional dos Procuradores do Trabalho (ANPT) e Associação Nacional dos Procuradores da República (ANPR), denota-se argumentos que se materializam na violação dos pilares da Constituição, especialmente no que se refere aos cuidados com a sociedade em geral, haja vista que é atribuído ao Estado conceder o mínimo como saúde, educação, igualdade social, segurança, entre outros. Aduzem que o novo regime fiscal impõe um nítido retrocesso e implica em insegurança para a sociedade como um todo, uma vez que que restringe, por vinte anos, os direitos fundamentais que garantem a dignidade humana. Argumentam, também, que a referida Emenda viola a autonomia funcional e administrativa do Ministério Público, uma vez que viola os dispositivos constitucionais concernentes à autonomia da Instituição.

Durante a tramitação da referida PEC, a Associação Nacional de Pesquisa em Financiamento da Educação (FINEDUCA) e a Campanha Nacional pelo Direito à Educação elaboraram uma Nota Técnica Conjunta ${ }^{5}$ abordando seus impactos para a educação, conclamando a votação contra todo o Projeto, uma vez que este compromete estruturalmente a maior conquista da educação brasileira, que foi a vinculação de um percentual da receita de impostos para a educação, definidos em um mínimo de $18 \%$ para a União e de $25 \%$ para estados e municípios. Os estudos realizados pelas duas entidades naquele contexto esclareciam como a PEC 241/55 inviabiliza o CAQi (Custo Aluno-Qualidade inicial), estratégia central para assegurar a todos os brasileiros uma escola com padrões básicos de qualidade, e o Plano Nacional de Educação. As entidades destacaram ainda que é um engodo pensar que essa medida representaria uma economia para os gastos públicos e afirmam que a PEC congela verbas para as políticas sociais para liberar recursos para pagamento da dívida pública e a especulação financeira. As entidades realizaram ainda uma prospecção dos impactos dessa medida na vinculação dos recursos da União, conforme o gráfico abaixo. A ilustração evidencia a gradativa e expressiva redução dos recursos da educação para o período de vigência da Emenda Constitucional.

5 Disponível em: <http://www.fineduca.org.br/wpcontent/uploads/2016/10/Nota-conjunta-FINEDUCACNDE_01_2016>. Acesso em: 06 maio 2017. 
Mutações da Face Social do Estado pela Emenda Constitucional 95 e seus Efeitos sobre as Políticas Educacionais

Figura 1 - Efeitos da PEC na vinculação da União (ano 1 = 18\%)

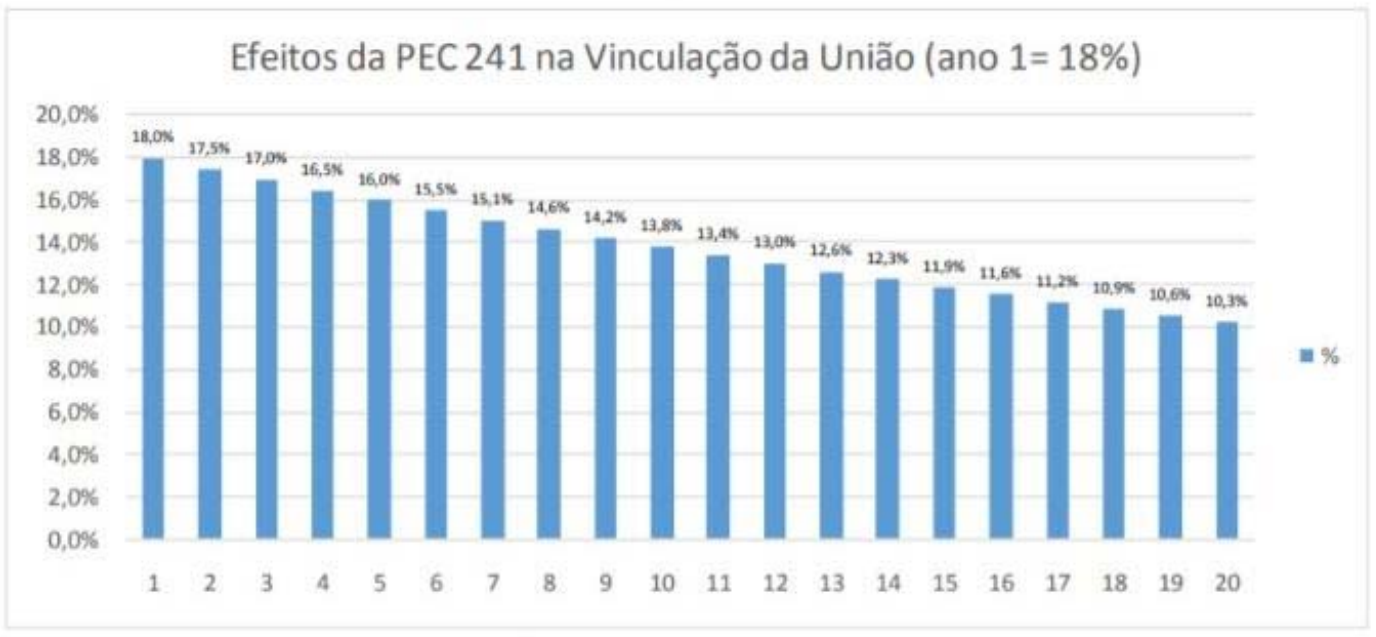

Fonte: Associação Nacional de Financiamento da Educação (2016).

Com efeito, as metas do Plano Nacional de Educação (2014-2024), regulamentado pela Lei $n^{\circ} 13.005 / 2014$, estão estruturalmente comprometidas, após a aprovação dos Projetos de Emenda Constitucional 241/16 e 85/16, consubstanciando-se na Emenda Constitucional $n^{\circ}$ 95 de 2016. O referido Plano contém um total de 20 metas, que permeiam diversas vertentes e, para que elas sejam cumpridas,

[...] há que se elevar o volume de recursos financeiros aplicados em educação: expandir o quantitativo de matriculados na educação básica (EB) e na educação superior (ES), tanto na graduação quanto na pós-graduação; melhorar o fluxo e a aprendizagem dos estudantes; alfabetizar na idade adequada; diminuir $\mathrm{o}$ analfabetismo; expandir a educação em tempo integral; elevar a qualificação dos professores da EB e aumentar a titulação dos professores da ES; elevar os salários dos professores da EB; incluir jovens com deficiência, transtornos globais de desenvolvimento e altas habilidades ou superdotação; elevar a escolaridade média da população - no campo, entre os mais pobres e negros -; aumentar a titulação dos professores da EB em nível de mestrado ou doutorado; assegurar planos de carreira para os profissionais da EB; efetivar a gestão democrática nas escolas e instituições; diminuir o percentual de estudantes matriculados nas instituições de educação superior (IES) privadas; elevar a proporção de mestres e doutores nos corpos docentes das IES privadas; e formar, em nível de pós-graduação, a metade dos professores da EB (BRASIL apud AMARAL, 2017, p. 6).

Ressaltamos ainda a meta 20 do Plano Nacional de Educação, que preconiza "[...] ampliar o investimento público em educação pública de forma a atingir, no mínimo, o patamar de $7 \%$ (sete por cento) do Produto Interno Bruto - PIB do País no $5^{\circ}$ (quinto) ano de vigência desta Lei e, no mínimo, o equivalente a $10 \%$ (dez por cento) do PIB ao final do decênio". Dessarte, a Emenda Constitucional 95 compromete estruturalmente a materialização da referida meta, uma vez que, para cumprir os compromissos, será preciso elevar os recursos públicos aplicados em educação. Ao contrário dessa perspectiva, presenciamos uma expressiva redução orçamentária, e com a aprovação da Emenda 95/2016 está suspensa até 2036 a eficácia do inciso I do $\S 2^{\circ}$ do art. 198 e do caput do art. 212 da CF, que estabelecem, respectivamente, pisos mínimos de gastos pela União com saúde e educação, que ficam desvinculados da arrecadação. 
Mutações da Face Social do Estado pela Emenda Constitucional 95 e seus Efeitos sobre as Políticas Educacionais

\section{Considerações Finais}

A Emenda Constitucional 95, ao congelar o financiamento para a educação, saúde, seguridade social até 2036, compromete estruturalmente o Plano Nacional de Educação como também o artigo 212 da Constituição Federal, que determina a aplicação de no mínimo 18\% da receita líquida de impostos da União em manutenção e desenvolvimento do ensino. Além disso, de acordo com Projeções do IBGE, em 2036 a população brasileira terá um crescimento de, pelo menos, 20 milhões de pessoas, com aumento significativo da população idosa, provavelmente o dobro da que se tem hoje. Isso significa maior demanda por serviços de saúde. Diante desse quadro, a despesa per capita não será apenas congelada, mas sofrerá redução.

Diante desse panorama, a Emenda Constitucional 95 enseja uma dupla tensão: a preservação das conquistas sociais traduzidas em dispositivos constitucionais $\mathrm{e} o$ cerceamento da garantia dos direitos fundamentais, sobretudo aos estratos empobrecidos. Tal paradoxo leva-nos a corroborar a tese da Procuradoria Geral dos Direitos do Cidadão do Ministério Público Federal ${ }^{6}$ ao afirmar que tais reformas poderiam ocorrer apenas no âmbito do poder constituinte originário e jamais no poder de reforma. Assim, há inconsistências de várias naturezas na EC 95, desde sua propositura até o teor de seu conteúdo, conforme apresentamos na seção anterior.

Os direitos fundamentais somente foram incorporados ao nosso arcabouço jurídico a partir da luta dos que nos precederam. Calar-se agora significa desrespeitar séculos de conquistas. É por isso que se fala no princípio da proibição de retrocesso. Ainda que os direitos sociais não sejam expressamente cláusulas pétreas da Constituição, não se pode admitir o retrocesso na sua proteção.

As reivindicações presentes nas históricas lutas em prol da educação pública, gratuita, laica e socialmente referenciada, foram, em boa medida, incorporadas pela Constituição Federal, promulgada há três décadas. Não obstante as conquistas sociais estarem em risco, no campo da educação, especificamente haverá uma expressiva redução de recursos públicos destinados ao financiamento da educação (artigo 110 do ADCT). Assim, os entes federativos padecerão de intensas dificuldades no processo de garantias da oferta e de melhorias do ensino, atingindo de forma crucial os estratos empobrecidos da população, uma vez que são os principais beneficiários das políticas públicas. Ademais, o princípio constitucional da igualdade também será atingido, uma vez que as principais políticas de enfrentamento às desigualdades econômicas e sociais (educação, saúde e seguridade social) estarão intrinsecamente comprometidas, enfraquecendo ainda mais as premissas do Estado Democrático de Direito, notadamente o objetivo contido do art. $3^{\circ}$, III, qual seja, a redução das desigualdades sociais e regionais.

Os objetivos constitucionais do art. $3^{\circ}$ da Constituição do Brasil, embora se configurem como normas programáticas, são possuidores de uma eficácia indicadora de um caminho e a Emenda 95 direciona o País para um rumo completamente diferente. Não é dado ao

6 Documento disponível em: <http://pfdc.pgr.mpf.mp.br/atuacao-e-conteudos-de-apoio/temas-deatuacao/direitos-humanos/atuacao-do-mpf/conjunto-de-argumentos-pela-inconstitucionalidade-da-ec-952016>. Acesso em: 19 set. 2018 
Mutaç̃es da Face Social do Estado pela Emenda Constitucional 95 e seus Efeitos sobre as Políticas Educacionais

Constituinte Derivado fraudar as orientações básicas do Constituinte Originário, pois seria uma completa distorção da essência do Texto de 1988, que é uma Constituição Social.

A análise dos conteúdos das sete Ações Diretas de Inconstitucionalidade, enfocadas neste artigo, possibilita-nos concluir que a medida infringe dispositivos constitucionais relativos ao núcleo essencial de direitos fundamentais, ofendendo aspectos cruciais da Carta Magna, devendo ser declarado inconstitucional o artigo 110 do Ato de Disposições Transitórias (ADCT), no qual se prevê a alteração dos gastos mínimos em educação e saúde. Urge, pois, que o Supremo Tribunal Federal aprove as Ações Diretas de Inconstitucionalidade ajuizadas naquela instância, ou senão que o novo Parlamento, na legislatura que iniciou em 2019, revogue a Emenda Constitucional 95. Destarte, cabe às entidades de classe, movimentos sociais e sociedade civil em geral criar mecanismos de mobilização para pressionar a esfera judiciária (STF) e a esfera legislativa (Congresso Nacional) e fazer valer o princípio do Estado Democrático de Direito presente na Constituição Federal de 1988, o qual tem como base a participação popular, que deve ser entendida como o exercício pleno da cidadania.

\section{Referências}

ADI questiona alteração de gratificação e devolução de funcionários de prisões no PR. Supremo Tribunal Federal, Brasília, 01 dez. 2017.

AFONSO, A. J. Protagonismos Instáveis dos Princípios de Regulação e Interfaces Público/Privado em Educação. Educação \& Sociedade, Campinas, v. 31, n. 113, p. 11371156, out./dez. 2010.

AMARAL, N. C. Com a PEC 241/55 (EC 95) haverá prioridade para cumprir as metas do PNE (2014-2024)? Revista Brasileira de Educação, Rio de Janeiro, v. 22 n. 71, 2017.

BRASIL. Palácio do Planalto. Constituição da República Federativa do Brasil de 1988. Diário Oficial da União, Brasília, 1988. Disponível em: <http://www.planalto.gov.br/ccivil_03/ constituicao/constituicaocompilado.htm>. Acesso em: 19 jun. 2018.

CANOTILHO, J. J. G. Constituição dirigente e vinculação do legislador: contributo para a compreensão das normas constitucionais programáticas. Reimpressão. Coimbra: Coimbra Editora, 1994. p. 169-170.

FINEDUCA. Associação Nacional de Financiamento da Educação. Nota técnica Fineduca e Campanha: a aprovação da PEC 241 significa estrangular a educação pública brasileira e tornar letra morta o Plano Nacional de educação 2014-2014. São Paulo, 2016. Disponível em: $<$ http://www.fineduca.org.br/wpcontent/uploads/2016/10/Nota-conjunta-FINEDUCACNDE_01_2016>. Acesso em: 06 maio 2017.

GRAMSCI, A. Cadernos do cárcere: Maquiavel, notas sobre o Estado e a política. Rio de Janeiro: Civilização Brasileira, 2000. v. 3.

HOFLING, E. Estado e políticas (públicas) sociais. Cadernos Cedes, Campinas, ano XXI, n. 55, nov. 2001.

MARX, K. Crítica da filosofia do direito de Hegel. Tradução de Rubens Enderle e Leonardo de Deus. Supervisão e notas Marcelo Backes. 2. ed. revista. São Paulo: Boitempo, 2010. 
Mutaç̃es da Face Social do Estado pela Emenda Constitucional 95 e seus Efeitos sobre as Políticas Educacionais

MEIRELLES, H. Proposta de Emenda à Constituição. Brasília, 2016. Disponível em: <https://www.camara.leg.br/proposicoesWeb/prop_mostrarintegra;jsessionid=DBEE55DED7 C8D9D5DF43EA9B7477467F.proposicoesWebExterno2?codteor=1468431\&filename=Trami tacao-PEC+241/2016>. Acesso em: 12 jun. 2016.

OLIVEIRA, E. Parecer nº 920, de 2016-PLEN. Brasília, 2016.

PERONDI, D. Proposta de Emenda à Constituição n 241-a, de 2016. Câmara dos Deputados. Comissão Especial destinada a proferir parecer à Proposta de Emenda à Constituição $n^{\circ} 241$ A, de 2016, do Poder Executivo, que "altera o Ato das Disposições Constitucionais Transitórias, para instituir o Novo Regime Fiscal”. Diário Oficial da União, Brasília, 2016. Disponível em: <https://www.camara.leg.br/proposicoesWeb/prop_mostrarintegra?co dteor=1496691\&filename=Tramitacao-PEC+241/2016>. Acesso em: 12 jun. 2019.

SANTOS, B. S. A gramática do tempo: para uma nova cultura política. Porto: Afrontamento, 2006.

SUPREMO TRIBUNAL FEDERAL. Ação Direta de Inconstitucionalidade (Med. Liminar). 5633. Brasília, 2016. Disponível em <http://portal.stf.jus.br/processos/detalhe .asp? incidente=5112200>. Acesso em: 08 maio 2019.

SUPREMO TRIBUNAL FEDERAL. Ação Direta de Inconstitucionalidade (Med. Liminar). 5643. Brasília, 2017a. Disponível em: <http://www.stf.jus.br/portal/peticaolnicial/verPetica olnicial. asp?base=ADIN\&s1=5643\&processo=5643>. Acesso em: 10 maio 2019.

SUPREMO TRIBUNAL FEDERAL. Ação Direta de Inconstitucionalidade (Med. Liminar). 5658. Brasília, 2017b. Disponível em: <http://www.stf.jus.br/portal/peticaolnicial/verPet icaolnicial .asp?base=ADIN\&s1=5658\&processo=5658>. Acesso em: 10 maio 2019.

SUPREMO TRIBUNAL FEDERAL. Ação Direta de Inconstitucionalidade (Med. Liminar). 5680. Brasília, 2017c. Disponível em: <http://portal.stf.jus.br/processos/detalhe.asp?inci dente $=5157574>$. Acesso em: 10 maio 2019.

SUPREMO TRIBUNAL FEDERAL. Ação Direta de Inconstitucionalidade (Med. Liminar). 5715. Brasília, 2017d. Disponível em: <http://www.stf.jus.br/portal/peticaolnicial/verPetic aolnicial.asp?base=ADIN\&s1=5715\&processo=5715>. Acesso em: 10 maio 2019.

SUPREMO TRIBUNAL FEDERAL. Ação Direta de Inconstitucionalidade (med. liminar). 5734. Brasília, 2017e. Disponível em: <http://www.stf.jus.br/portal/peticaolnicial/verPetica olnicial.asp?base=ADIN\&s1=5734\&processo=5734>. Acesso em: 10 maio 2019.

Maria Vieira Silva é doutora em Educação pela UNICAMP com estágio pós-doutoral no Centre de Recherches Sociologiques et Politiques de Paris - França. Professora da Faculdade de Educação da Universidade Federal de Uberlândia com atuação no Programa de PósGraduação em Educação (Mestrado e Doutorado) desta mesma Instituição.

ORCID: https://orcid.org/0000-0002-4510-0844

E-mail: mvieiraufu@gmail.com

Ana Júlia Eugênio é graduada em Direito pela Universidade Federal de Uberlândia. Especialização em Direito Tributário pelo Instituto de Estudos Tributários - IBET. 
Mutações da Face Social do Estado pela Emenda Constitucional 95 e seus Efeitos sobre as Políticas Educacionais

ORCID: https://orcid.org/0000-0003-2669-3389

E-mail: ajeugeniof@hotmail.com

Helen Corrêa Solis Neves é graduada em Direito pela Universidade Federal de Uberlândia. Mestrado em Direito pela Universidade Católica de Brasília. Professora do Centro Universitário do Triângulo.

ORCID: https://orcid.org/0000-0003-0774-1859

E-mail: helensolis@gmail.com

Recebido em 13 de junho de 2019

Aprovado em 09 de dezembro de 2019 


\section{Editores do volume 10}

Márcia Aparecida Jacomini - Universidade Federal de São Paulo, Brasil

José Marcelino de Rezende Pinto - Universidade de São Paulo, Brasil

\section{Comitê Editorial}

Nalú Farenzena - Universidade Federal do Rio Grande do Sul, Brasil

Juca Gil - Universidade Federal do Rio Grande do Sul, Brasil

Theresa Adrião - Universidade Estadual de Campinas, Brasil

Ângelo Ricardo de Souza - Universidade Federal do Paraná, Brasil

\section{Conselho Editorial}

\section{Alejandro Morduchowicz}

Universidad Pedagógica, Provincia de Buenos Aires, Argentina

Andréa Barbosa Gouveia

Universidade Federal do Paraná, Brasil

Fernanda Saforcada

Universidade de Buenos Aires, Argentina

Jacques Velloso

Universidade de Brasília, Brasil

João Monlevade

Senado Federal, Brasil

Jorge Abrahão de Castro

Instituto de Pesquisa Econômica Aplicada / IPEA, Brasil

Lisete Regina Gomes Arelaro

Universidade de São Paulo, Brasil

Luis Carlos Sales

Universidade Federal do Piauí, Brasil

Luiz de Sousa Junior

Universidade Federal da Paraíba, Brasil

Luiz Fernandes Dourado

Universidade Federal de Goiás, Brasil

Magna França

Universidade Federal do Rio Grande do Norte, Brasil

Marcos Edgar Bassi

Universidade Federal de Santa Catarina, Brasil

Maria Angélica Pedra Minhoto

Universidade Federal de São Paulo, Brasil

Maria Beatriz Luce

Universidade Federal do Rio Grande do Sul, Brasil

Maria Dilnéia Espíndola Fernandes

Universidade Federal de Mato Grosso do Sul, Brasil

Nelson Cardoso do Amaral

Universidade Federal de Goiás, Brasil

Nicholas Davies

Universidade Federal Fluminense, Brasil

Robert E. Verhine

Universidade Federal da Bahia, Brasil

Romualdo Portela de Oliveira

Universidade de São Paulo, Brasil

Rosana Gemaque Rolim

Universidade Federal do Pará, Brasil

Rubens Barbosa de Camargo

Universidade de São Paulo, Brasil

Theresa Adrião

Universidade Estadual de Campinas, Brasil

Tristan McCowan

University of London, Reino Unido

Vera Jacob

Universidade Federal do Pará, Brasil

Vera Peroni

Universidade Federal do Rio Grande do Sul, Brasil

Vitor Henrique Paro

Universidade de São Paulo, Brasil

\section{Equipe editorial}

Apoio ao Comitê Editorial: Caio Cabral da Silva

Diagramação, Revisão de português e normalização: Edson Leonel de Oliveira

Revisão de inglês: Sabrina Ferreira

Fineduca - Revista de Financiamento da Educação

Associação Nacional de Pesquisa em

Financiamento da Educação

e-mail: revista.fineduca@gmail.com | site: http://seer.ufrgs.br/fineduca 